\title{
Cota tinctoria and Orosius albicinctus: A new plant host and potential insect vector of 'Candidatus Phytoplasma trifolii'
}

\author{
Chamran Hemmati ${ }^{1,2}$ (D) Mehrnoosh Nikooei $^{1} \cdot$ Hossein Pasalari $^{1}$
}

Received: 3 March 2018 / Accepted: 26 April 2018 / Published online: 2 May 2018

(C) Australasian Plant Pathology Society Inc. 2018

\begin{abstract}
Samples of Cota tinctoria with phytoplasma symptoms including witches' broom, stunting, twisting of the shoots and little leaf were observed in Bandar Abbas, Iran, in 2017. Phylogenetic analysis revealed that the phytoplasma associated with Cota tinctoria witches' broom (CtWB) is a strain of 'Candidatus Phytoplasma trifolii'. Furthermore, the phytoplasma was successfully detected in the leafhopper, Orosius albicinctus collected from the symptom-bearing plants. This work therefore reports a new phytoplasma-associated disease on Cota tinctoria and its putative insect vector.
\end{abstract}

Keywords Golden marguerite · Phytoplasma · Potential vector · Witches' broom

Phytoplasmas (wall-less and phloem-restricted plant pathogenic bacteria) are recognized as a serious constraint for the cultivation of many ornamental plants around the world. They can reduce the quality and yield of ornamental plants because of their unspecific symptoms and can cause severe losses (Bertaccini and Duduk 2010). Epidemics of these diseases have limited the cultivation of many ornamental plant species such as gladiolus, lily, chrysanthemum and rose. Phytoplasmas affect more than 600 plant species from tropical, subtropical to temperate climates all over the world (Jones 2002). The general symptoms include flower malformation, growth abnormalities, yellowing of leaves, elongation and etiolation of internodes, witches' broom, stunting, little leaf and virescence (Chaturvedi et al. 2010). In plant disease epidemics, insect vectors play a major role. Furthermore, polyphagous vectors have the potential to inoculate a wide range of plant species, which may differ in susceptibility (Weintraub and Beanland 2006).

Cota tinctoria, also known as golden marguerite, yellow chamomile, is a species of perennial flowering plant in the Asteraceae family. It is a short-living plant often treated as biennial, native to Europe, the Mediterranean and Western Asia and naturalized in scattered locations in North America

Chamran Hemmati

Chamran.hemmati@hormozgan.ac.ir

1 Department of Agriculture, Faculty of Agriculture and Natural Resources, University of Hormozgan, Bandar Abbas, Iran

2 Plant Protection Research Group, University of Hormozgan, Bandar Abbas, Iran
(Franke 2005). It produces excellent yellow, buff and goldenorange dyes, used in the past for fabrics. This species is grown in gardens for its bright attractive flowers and fine lacy foliage, and in Iran, especially in southern regions, this species is widely planted as an ornamental plant in green landscapes. So far, no diseases and pests have been reported on Cota tinctoria.

In January 2017, during a survey, typical symptoms of phytoplasma disease, including witches' broom, stunting, twisting of the shoots and little leaf were observed in several Cota tinctoria flowers planted in a green landscape in Bandar Abbas, Hormozgan province, Iran (Fig. 1). A preliminary study to determine whether a phytoplasma was associated with the symptom-bearing plant was performed. Simultaneously, insect samples, mainly planthoppers and leafhoppers (Cicadellidae), were collected using yellow sticky cards. The yellow sticky cards were replaced at weekly intervals and species were captured and checked for phytoplasma presence. Insects were preserved in absolute acetone until DNA extraction (Fukatsu 1999).

Ten samples of both symptom-bearing and three samples of asymptomatic Cota tinctoria were collected from green land-

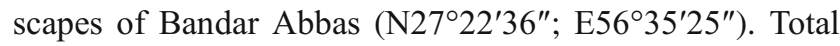
DNA was extracted from leaves of all collected symptombearing and symptomless samples by using the cetyltrimethylammoniumbromide (CTAB) extraction procedure described by Sahu et al. (2012). Total DNA was extracted from ten individual leafhoppers using the CTAB protocol described by Reineke et al. (1998).

To determine the presence of phytoplasmas in Cota tinctoria and insect samples, a nested polymerase chain 
Fig. 1 Symptoms of witches' broom, little leaf (a), stunting and twisting of the shoot (b) in comparison with healthy Cota tinctoria $(\mathbf{c})$
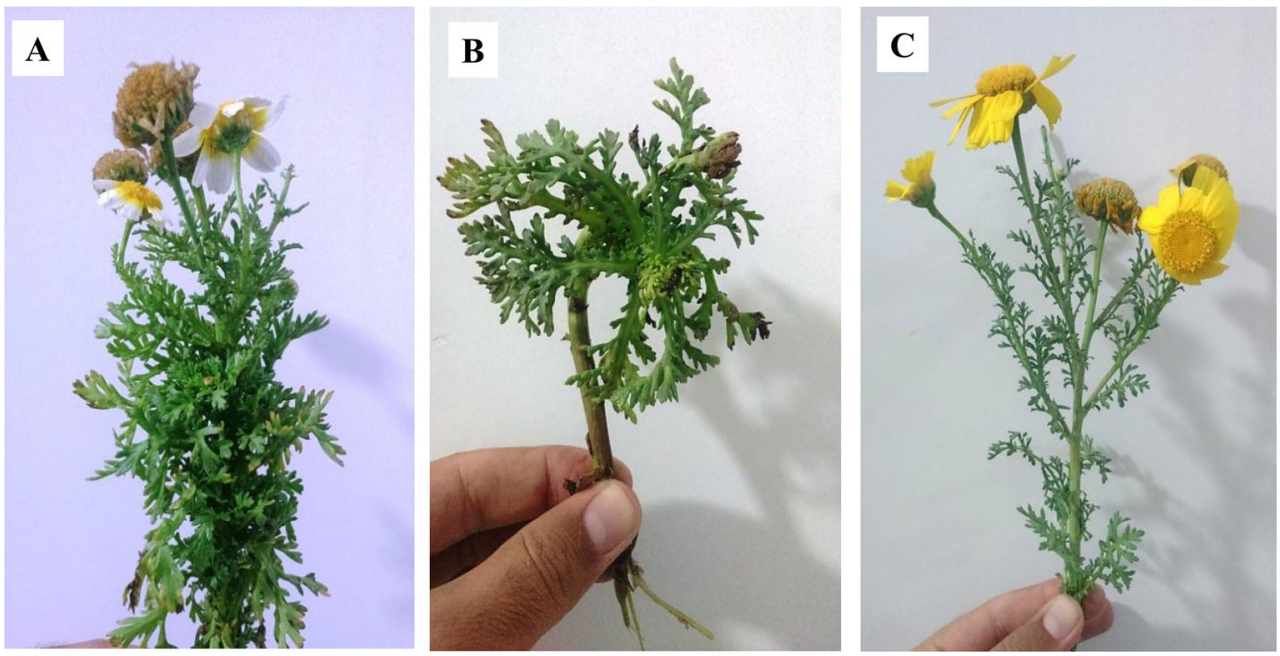

reaction (PCR) was employed using the universal primers $\mathrm{P} 1 /$ P7 (Deng and Hiruki 1991) followed by R16F2n/R16R2 which amplifiy a phytoplasma16S rRNA fragment (approximately $1.25 \mathrm{kbp}$ ). PCR assays were performed with $50 \mu \mathrm{l}$ reactions containing $1 \mu \mathrm{M}$ of each primer, $25 \mu \mathrm{l}$ master mix

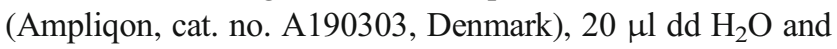
$3 \mu \mathrm{l}$ template DNA. PCR conditions for amplification were denaturation at $94^{\circ} \mathrm{C}$ for $3 \mathrm{~min}$ followed by 35 cycles of $94^{\circ} \mathrm{C}$ for $45 \mathrm{~s}, 55^{\circ} \mathrm{C}$ for $1 \mathrm{~min}$ and $72{ }^{\circ} \mathrm{C}$ for $1.5 \mathrm{~min}$, with a final extension of $10 \mathrm{~min}$ at $72{ }^{\circ} \mathrm{C}$. One microlitre of 1:10 diluted first amplification product was used as DNA template in the second round (nested) PCR. Nested-PCR conditions were the same used in a first round, while annealing temperature for the second round was $56{ }^{\circ} \mathrm{C}$. 'Candidatus Phytoplasma aurantifolia' and DNA template free were used as positive and negative control, respectively. To identify the insect species, PCR amplification of partial mitochondrial COI (cytochrome oxidase I) gene was performed using LCO1490 and HCO2198 primers (Folmer et al. 1994). The PCR was performed in $25 \mu$ l solution contained $12.5 \mu \mathrm{l}$ master mix (Ampliqon, cat. no. A190303, Denmark), $1 \mu$ of each primer (10 pmol $/ \mu \mathrm{l}), 1 \mu \mathrm{l}$ of extracted DNA and $9.5 \mu \mathrm{ldd}$ water. The thermocycling program consisted of an initial denaturation step at $95{ }^{\circ} \mathrm{C}$ for $3 \mathrm{~min}$, followed by 5 cycles of $1 \mathrm{~min}$ at $94{ }^{\circ} \mathrm{C}, 1 \mathrm{~min}$ at $45^{\circ} \mathrm{C}, 1 \mathrm{~min}$ at $72^{\circ} \mathrm{C}$, and then 35 cycles of $1 \mathrm{~min}$ at $94{ }^{\circ} \mathrm{C}, 1 \mathrm{~min}$ at $51^{\circ} \mathrm{C}, 1 \mathrm{~min}$ at $72{ }^{\circ} \mathrm{C}$, with a final extension step at $72{ }^{\circ} \mathrm{C}$ for $5 \mathrm{~min}$.

The amplified fragments were electrophoresed on $1.0 \%$ agarose gel stained with FluoroDye under UV light and phytoplasma was detected as nested PCR products of approximately $1250 \mathrm{bp}$ (16S rRNA) from five separate symptomatic plants using the R16F2n/ R16R2 primer pair. Similarly, amplification products were obtained from positive control samples but not in the assays of samples from non-symptomatic plants and negative controls. Insects collected on the symptom-bearing plants were also identified and checked for phytoplasma presence using PCR assays and Orosius albicinctus (Distant, 1918) was the dominant and only positive species in which PCR and subsequently sequencing results confirmed presence of the phytoplasma. Eight out of ten tested individuals showed PCR bands of the correct size, confirming presence of phytoplasma.

To confirm the presence of phytoplasma and for phylogenetic analysis, two fragments (one plant, one insect) were randomly selected from the nested PCR round and sequenced bidirectional by using primer R16F2n/ R16R2 while one fragment of COI gene was sequenced directly using LCO1490 and $\mathrm{HCO} 2198$ primers. The obtained COI sequence was analysed using GenBank, by NCBI-BLAST to find the closest match. Raw sequence chromatograms were assembled and edited using DNAstar (Hall 1999) to correct ambiguous bases or remove low quality stretches from termini of the sequences. Homologies to known sequences were detected using the BLASTN algorithms against the non-redundant GenBank database. Phylogenetic analyses were conducted by neighbor joining (NJ) methods using MEGA 6.0 software (Tamura et al. 2013). The 16S rRNA sequences of phytoplasma used in a comprehensive phylogenetic analysis were downloaded from GenBank (the accession numbers are given in brackets in fig. 2).

BLAST analysis of the partial 16S rRNA sequence from the plant sample (Accession No. MG569790) revealed that the phytoplasma associated with Cota tinctoria witches' broom shared $99 \%$ identity with some phytoplasmas related to the 16SrVI phylogenetic group 'Candidatus Phytoplasma trifolii' such as Tomato big bud (accession no. JF508508), 'Candidatus Phytoplasma trifolii' (KX773529), Zuccini phyllody (accessionno. KP119494). The phylogenetic tree was in accordance with BLAST analysis and the sequence from the present study was clustered in group 16SrVI (Fig. 2). This result was further confirmed by the analysis using the $i$ PhyClassifier online tool (Zhao et al. 2009) (http:// 


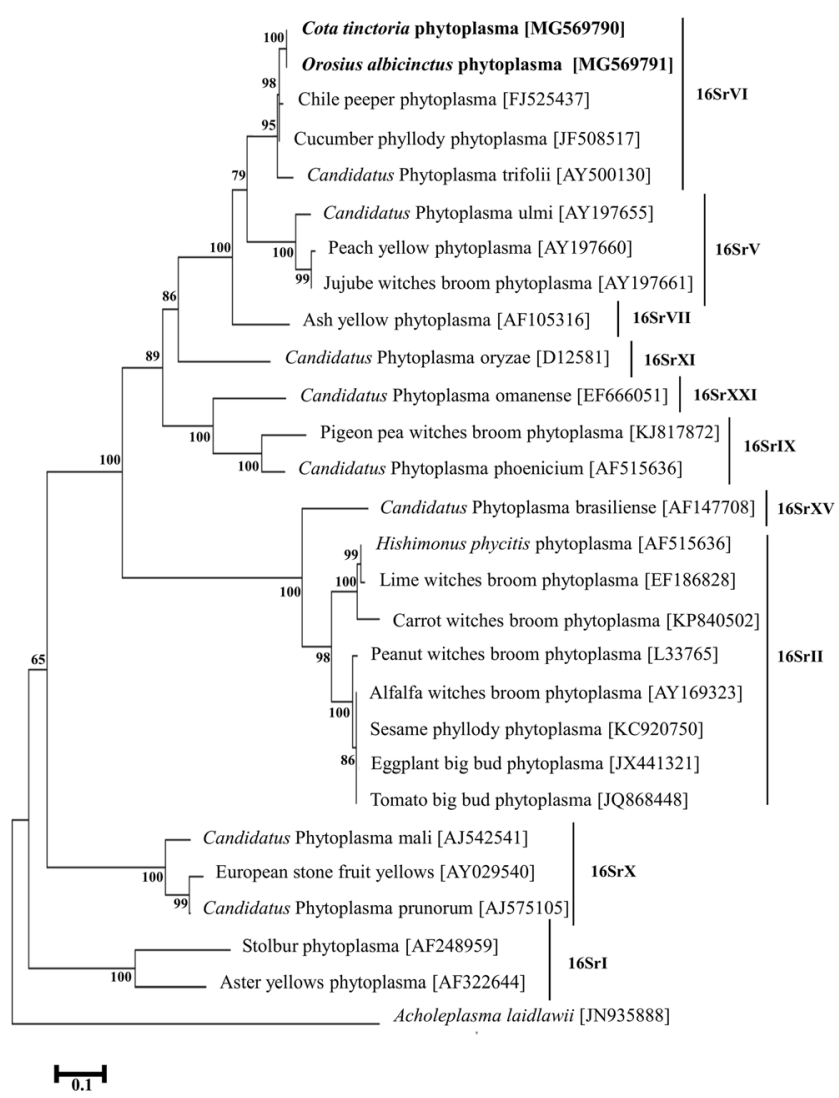

Fig. 2 Phylogenetic tree of partial 16S rRNA gene sequences from Cota tinctoria witches' broom phytoplasma isolates (marked in bold) and selected phytoplasma reference sequences. GenBank accession numbers are shown in brackets, and $16 \mathrm{Sr}$ groups are annotated to the right. Acholeplasma laidlawii was used as the outgroup to root the tree. The tree was constructed by the neighbor-joining method using MEGA 6 software. The bar indicates the number of nucleotides substitution per site. Bootstrap values are shown at nodes with greater than 50\% support

plantpathology.ba.ars.usda.gov/cgi-bin/resource/iphyclassifier. cgi) where it was determined that the $C$. tinctoria phytoplasma was related to $16 \mathrm{SrVI}$ group, subgroup A.

The sequence obtained from insects was aligned (Clustal Omega) with that obtained from symptomatic plants which revealed $100 \%$ similarity. The nucleotide sequence of the phytoplasma isolated from insect was deposited in the GenBank database (Accession No. MG569791) and the sequence obtained from the insect was placed in a clade with that isolated from plants (Fig. 2). Insect COI gene sequence showed 100\% identity with Orosius albicinctus. Based on these results, O. albicinctus can be considered as a potential vector of this disease on $C$. tinctoria in this region in southern Iran. This species has been reported previously as a vector of alfalfa witches' broom, cucumber phyllody, garden beet witches' broom and sesame phyllody (Omidi et al. 2010) in Iran which reinforces the hypothesis that this species could be an insect vector of this disease to other flowers. However, vectoring capability can only be confirmed by transmission assays. Orosius albicinctus is distributed in Iran, Australia, Fiji,
Indonesia, New Britain and Gava, Israel, Egypt, India (Pakarpour Rayeni and Seraj 2016).

Based on the virtual RFLP results and phylogenetic analysis of the 16S rRNA gene sequences, it can be concluded that the phytoplasma detected in the symptomatic C. tinctoria in Hormozgan province belongs to the $16 \mathrm{SrVI}$ group, subgroup A. In Iran, group16SrVI phytoplasmas have been identified in a number of hosts including Carthamus tinctorius, Cucumis sativus, Medicago sativa and Suaeda aegyptiacae (Askari Seyahooei et al. 2017). To the author's knowledge, this is the first report of a phytoplasma disease associated with Cota tinctoria plants with a substantial population of the $O$. albicinctus leafhopper as a potential vector.

\section{References}

Askari Seyahooei M, Hemmati C, Faghihi MM, Bagheri A (2017) First report of a 'Candidatus Phytoplasma trifolii'-related strain associated with Suaeda aegyptiaca and its potential vector in Iran. Australas Plant Dis Notes 12(1):24

Bertaccini A, Duduk B (2010) Phytoplasma and phytoplasma diseases: a review of recent research. Phytopathol Mediterr 48(3):355-378

Chaturvedi Y, Rao G, Tiwari A, Duduk B, Bertaccini A (2010) Phytoplasma on ornamentals: detection, diversity and management. Act Phytopathol Entomol Hung 45(1):31-69

Deng S, Hiruki C (1991) Amplification of 16Sr RNA genes from culturable and non-culturable mollicutes. J Microbiol Methods 14: 53-61

Folmer O, Black M, Hoeh W, Lutz R, Vrijenhoek R (1994) DNA primers for amplification of mitochondorial cytochrome $\mathrm{c}$ oxidase subunit I from diverse metazoan invertebrates. Mol Mar Biol Biotechnol 3: 294-297

Franke R (ed) (2005) Plant sources. Chamomile: Ind Profiles 1:39-42

Fukatsu T (1999) Acetone preservation: a practical technique for molecular analysis. Mol Ecol 8(11):1935-1945

Hall TA. (1999) BioEdit: a user-friendly biological sequence alignment editor and analysis program for Windows 95/98/NT. Nucleic acids symposium series. Vol. 41. No. 41. [London]: Information Retrieval Ltd., c1979-c2000

Jones P (2002) Phytoplasma plant pathogens. In: Waller M, Lenne JM, Waller SJ (eds) Plant pathologists pocketbook. CAB International, Chapter 12, Wallingford, Oxfordshire, UK, pp 126-139

Omidi MA, Hosseini Pour H, Massumi R, Rahimian H (2010) Investigation on Transmittance status of Orosius albicinctus (Hemiptera: Cicadellidae) as a natural vector of phytoplasmas in southeastern Iran. J Plant Pathol 1:531-535

Pakarpour Rayeni F, Seraj AA (2016) Review of the leafhopper genus Neoaliturus Distant (Hemiptera: Cicadellidae: Deltocephalinae) from Iran. J Insect Biodivers Syst 2:381-394

Reineke AP, Karlovsky P, Zebitz W (1998) Preparation and purification of DNA from insects for AFLP analysis. Insect Mol Biol 7(1):95-99

Sahu KS, Thangaraj M, Kathiresan K (2012) DNA extraction protocol for plants with high levels of secondary metabolites and polysaccharides without using liquid nitrogen and phenol. Mol Biol. https:// doi.org/10.5402/2012/205049

Tamura K, Stecher G, Peterson D, Filipski A, Kumar S (2013) MEGA6: Molecular Evolutionary Genetics Analysis Version 6.0. Mol Biol Evol 30:2725-2729 
Weintraub PG, Beanland L (2006) Insect Vectors of Phytoplasmas. Annu Rev Entomol 59:91-111

Zhao Y, Wei W, Lee IM, Shao J, Suo XB, Davis RE (2009) Construction of an interactive online phytoplasma classification tool,
iPhyClassifier, and its application in analysis of the peach $\mathrm{X}$ disease phytoplasma group (16SrIII). Int J Syst Evol Microbiol 59: $2582-2593$ 